\title{
Educational Technologies of the Fourth Industrial Revolution in the Context of the Covid-19 Pandemic
}

\author{
Rodnyansky D.V. ${ }^{1,2, *}$ Abramov R.A. ${ }^{2}$ Bulgakova V.N. ${ }^{1}$ \\ ${ }^{1}$ Kazan Federal university, Kazan, 420008, Russia \\ ${ }^{2}$ Plekhanov Russian university of economics, Moscow, Russia \\ ${ }^{*}$ Corresponding author.Email: drodnyansky@gmail.com
}

\begin{abstract}
The COVID-19 pandemic has changed more than just tourism, air travel and related industries. All industries have felt the change, leading to the term new normality. Significant changes have also taken place in the field of higher education. First of all, in connection with the transition to distance learning, educational tools of the fourth industrial revolution began to develop more actively. In the context of a new emerging technological order, the need for specialists who can work in rapidly changing working conditions, with the possibility of obtaining continuous education, is increasing. In response to new unfavorable sanitary and epidemiological conditions in higher education, new technologies are being actively introduced into the educational process and new methods of control and management are being formed. The article analyzes the performance indicators of universities from the 5-100 program in the process of introducing and implementing educational technologies of the fourth industrial revolution
\end{abstract}

Keywords: education, higher education, universities efficiency, innovations, fourth industrial revolution

\section{INTRODUCTION}

COVID-19 pandemic has accelerated transformation of the existing way of functioning of physical, biological, digital technologies.

Trends in changing the structure of society associated with the development of modern technologies, the process of globalization and international cooperation create the need for the development of universities, which are a source of competitive personnel and the main link in the process of creating scientific potential necessary to increase the influence of Russian higher education on the world arena of educational services. The changing paradigm of higher education leads to an increase in the role of universities in the development of regions and the country as a whole, and the forthcoming fourth industrial revolution, caused by the formation of a new technological order, leads to the process of transformation of life habitual for society.

The implementation of new technologies will make the transition to a new industrial revolution available. According to the author, in order to implement technological change within the framework of the concept of the Fourth Industrial Revolution, leaders must focus on "systems, not technologies." However, it is difficult to determine which production, government and social systems should be transformed. There are two ways to solve it: study the technology in detail and find out which system it belongs to, or evaluate the ongoing process and, on the basis of this, identify the connection with the latest technologies. The choice of the most accessible and optimal option, in accordance with the available opportunities, including technical, technological, human, informational and other potential, will ensure the implementation of changes to achieve a technological breakthrough.

Many authors conduct research on determining the place and role of modern universities in the chain of industrial products and the innovation system of society [ 1,2,3,4].

In connection with all of the above, many authors in their works study the issues of the effectiveness of universities both through a rating system and using more complex models $[5,6,7]$

Some scientists even consider universities as the main drivers for the development of regions, territories, and even the entire non-profit sector $[8,9,10]$.

Thus, the concept of the fourth industrial revolution dictates the need for radical transformations in the field of higher education, which is a source of personnel necessary for economic development and independence of the state, capable of changing the strategy of catch-up development to a strategy of advancing in certain industries and spheres, ensuring the technological leadership of the Russian Federation in the world. space. For this, conditions must be created under which specialists with competencies would be trained to work in new technological spaces. In addition, it is necessary to attract foreign personnel, whose experience will allow to achieve the necessary results in the field of scientific research.

Personnel are key participants in the ongoing changes, respectively, their training is a priority in the context of a change in the technological structure. The system of higher education is changing the current educational paradigm, which, in its inner content, must coincide with the changing paradigm of industrial production. The world educational system is currently undergoing structural changes, which 
consist in the active introduction of electronic means and distance learning. Distributed knowledge is becoming more and more available in almost all corners of the world through actively developing educational platforms. The boundaries between professional and academic education, formal and non-formal education are gradually blurring, personalization of education is increasing, which in turn strengthens the university's role as an integrator of scientific, educational, business and industrial environments, as well as the role of teachers as knowledge managers.

\section{METHODOLOGY}

The analysis of universities in the framework of the final qualification work for the use of technologies of the fourth industrial revolution was carried out on the basis of an integral assessment with further construction of the ranking of universities. The data was taken from university selfsurvey reports as well as the Internet.

The ranking was based on the technologies highlighted by K. Schwab, driving the fourth industrial revolution, divided into four blocks: digital technologies, the physical world, human changes, and environmental integration. Each of them contained three types of technologies, the presence of each of which was assessed as follows:

- the university uses technology in the educational process or scientific activity, or the scientific community is its developer for practical application - 1 point;

- the university provides training on this technology in educational programs, schools, projects - 0.5 points;

- technology is not applied at the university - 0 points.

Seven universities participating in Project 5-100, a program to improve the competitiveness of Russian higher educational institutions, except for the federal cities of Moscow and St. Petersburg, were selected as objects of research. These universities represent three groups, formed according to the pace of implementation of programs to increase competitiveness, according to which the differentiation of state support provided to universities is carried out, that is, the amount of subsidies allocated by the Government of the Russian Federation from the federal budget. The distribution of universities into groups is based on the assessment of three parameters: achievements in the ratings, the values of indicators characterizing the scientific, educational, international and financial activities of universities, as well as the presence of a clear system of development priorities.

The objects of research include:

- $\quad$ National Research University "Tomsk State University" (hereinafter - TSU) - 1 group;
- National Research University "Tomsk Polytechnic University" (hereinafter - TPU) group 2;

- $\quad$ Kazan Federal University (hereinafter - KFU) group 2;

- Ural Federal University (hereinafter - UrFU) group 2;

- National Research University "Nizhny Novgorod State University named after NI Lobachevsky "(hereinafter - UNN) - group 3;

- Far Eastern Federal University (hereinafter FEFU) - 3rd group;

- $\quad$ Siberian Federal University (hereinafter - SFU) 3rd group.

These universities are located, respectively, in six regions: the Tomsk region, the Republic of Tatarstan, the Sverdlovsk and Nizhny Novgorod regions, the Primorsky and Krasnoyarsk regions.

The sample is justified by the need to determine the correspondence of the positions in Project 5-100 and the level of implementation in the university of the elements of the fourth industrial revolution.

\section{RESULTS}

If the university conducts training on a specific technology, and at the same time it is used in the process of carrying out the activities of the university or is developed by scientific researchers, we gave one point for this university.

At the next stage, the integral indicators were calculated for each block according to the formula (1):

$$
\mathrm{I}_{\mathrm{i}}=\frac{\sum i}{n_{i}},
$$

where $n_{i}-$ the number of indicators in the block.

Table 1 shows the summary integral rating.

Further calculation of the composite integral index was carried out according to the formula (2):

$$
\mathrm{I}_{\mathrm{cв.}}=\frac{\sum I i}{n I} \text {, }
$$

where $\mathrm{n}_{\mathrm{i}}$ - the number of blocks, which is the arithmetic mean of the obtained block indices and allows you to compile the following rating. 
Table 1 The values of the integral indices of the average values by blocks

\begin{tabular}{|c|c|c|c|c|}
\hline University & $\begin{array}{c}\text { In the } \\
\text { field of } \\
\text { digital } \\
\text { technologi } \\
\text { es }\end{array}$ & $\begin{array}{c}\text { In the } \\
\text { field of } \\
\text { the } \\
\text { physical } \\
\text { world }\end{array}$ & $\begin{array}{c}\text { In the } \\
\text { field of } \\
\text { human } \\
\text { change }\end{array}$ & $\begin{array}{c}\text { In the field } \\
\text { of } \\
\text { environment } \\
\text { al } \\
\text { integration }\end{array}$ \\
\hline FEFU & 0,33 & 1 & 0,83 & 0,67 \\
\hline KFU & 0,67 & 1 & 0,83 & 0,83 \\
\hline NNSU & 0,67 & 1 & 0,67 & 0,33 \\
\hline TSU & 0,83 & 0,83 & 0,5 & 0,5 \\
\hline TPU & 0,83 & 0,83 & 0,33 & 0,67 \\
\hline UrFU & 0,83 & 1 & 0,67 & 0,5 \\
\hline SFU & 0,5 & 1 & 0,67 & 0,83 \\
\hline
\end{tabular}

As a result, the obtained values are ranked from maximum to minimum, which is a ranking of universities in terms of the degree of involvement in the transition to the fourth industrial revolution and the implementation of its elements. Table 2 . shows the resulting rating.

Table 2 Ranking of universities according to the level of implementation in the university of elements of the fourth industrial revolution

\begin{tabular}{|c|c|c|c|}
\hline University & $\begin{array}{c}\text { Summary } \\
\text { integral } \\
\text { index }\end{array}$ & Rating & $\begin{array}{c}\text { Group in } \\
\mathbf{5 - 1 0 0} \\
\text { program }\end{array}$ \\
\cline { 1 - 2 } KFU & 0,83 & 1 & 2 \\
\hline UrFU & 0,75 & \multirow{2}{*}{2} & 2 \\
\cline { 1 - 2 } SFU & 0,75 & & 3 \\
\hline FEFU & 0,71 & \multirow{2}{*}{3} & 3 \\
\hline TSU & 0,67 & & 1 \\
\hline NNSU & 0,67 & \multirow{2}{*}{4} & 3 \\
\cline { 1 - 2 } TPU & 0,67 & & 2 \\
\hline
\end{tabular}

Thus, the Kazan Federal University received the highest score for the implementation of the elements of the new industrial revolution with an index value of 0.83 , in which each of the given technologies is implemented. The next position was distributed between the Ural and Siberian federal universities, whose composite integral index is 0.75 in the absence of the implementation of one and two elements of the industrial revolution, respectively. The third in the ranking is the Far Eastern University, where two technologies are not implemented in the process of learning or carrying out activities - blockchain and geoengineering. Lagging behind, according to the ranking, are the Tomsk State, Tomsk Polytechnic and Nizhny Novgorod universities, which lack two technologies of the new industrial revolution, and for others, only training is more common.

Let us analyze whether the distribution in the groups of Project 5-100 corresponds to the rating of the implementation in the university of the elements of the fourth industrial revolution. For clarity, in table 2 added information about the affiliation of universities to a specific group.

\section{DISCUSSIONS}

Despite the fact that Tomsk State University is included in the first group of universities in its achievements in scientific, educational, international and financial activities, not all technologies of the fourth industrial revolution are implemented in a higher educational institution. The corresponding conclusion can be attributed to the Tomsk Polytechnic University, which is part of the second group of Project 5-100. On the contrary, the Siberian Federal University, which is part of the lagging group of the competitiveness improvement program, implements most of the given industrial technologies and uses them in the course of its activities. The remaining universities showed that the achievements assessed in Project 5-100 were consistent with the level of implementation of the fourth industrial revolution.

The result of the study is that under the current management system, the assessment of universities' activities does not include data on the use of modern technologies, which is an important criterion for determining the innovativeness of a university in the global educational space. Accordingly, this reveals a lag behind the most successful universities, which prevents the improvement of positions in international rankings and the strengthening of the competitiveness of Russian education.

With all this, it should be noted that Russian universities are moving to a new stage of development and are beginning to develop on their own and implement certain elements of the new industrial revolution. Let us characterize the experience of universities, which are the objects of research, on the basis of which the ranking was constructed.

At the Kazan Federal University, technologies related to the distributed ledger and blockchain are being developed and introduced into practice. Initially, blockchain technologies were used in cryptocurrencies, but recently, research and development have appeared in the field of their use in accounting systems, document management and other applications. In particular, the university has developed a software system that has been introduced into the work of the State Committee of the Republic of Tatarstan on archival affairs. In addition, Kazan University actively uses artificial intelligence and robotic systems in the oil and gas industry, medicine, as well as in working with information technology. Additive manufacturing technologies are developing in the field of prototyping, medicine, where, among other things, neurotechnologies, multidimensional printing, 3D printers, and laser systems are used. There is a possibility of using virtual and augmented reality technologies in the educational process to immerse students in the learning environment, for example, in the field of programming, practicing practical skills for students in simulators, and more. The priority areas of the Kazan Federal University are advanced materials, generation, 
storage and transfer of energy, space technologies, in which active work is being carried out.

As for the technologies developed at the Ural Federal University, one of them is computing technologies. The university develops software for various enterprises and provides professional training for software specialists, including using supercomputers. Also, active work is underway in the field of blockchain. The university has developed an NS blockchain platform for electricity management. The platform reduces electricity consumption, records data on its production and consumption, automatically issues electricity bills and much more. Students develop blockchain solutions for the real sector of the economy. In addition, the university introduces virtual reality and artificial intelligence technologies into the educational process, which create the necessary conditions for practicing practical skills. At the Ural Federal University, technologies are being developed that are classified as priority areas of scientific activity, such as new and advanced materials, energy, its production, accumulation and transfer.

Siberian Federal University implements blockchain technologies in the implementation of design work. One of these is a digital knowledge sharing and copyright management platform that collects and circulates copyright objects created in universities. Artificial intelligence and virtual reality technologies are used to consolidate and practice the acquired knowledge. Active work is underway in the field of biotechnology, fixed as the priority areas of the university. The technologies of additive manufacturing and multidimensional printing with the use of supercomputers are used. Research is also underway in the field of energy and space technologies, which are classified as strategic directions for the development of science.

Far Eastern Federal University specializes in artificial intelligence technologies embedded in industrial robots used to automate production. Students are taught using additive technologies, 3D printers and a supercomputer. Also, the university operates a Competence Center of the National Technological Initiative, the goal of which is to achieve world-class domestic developments in the field of neurotechnologies, virtual and augmented reality technologies. The Far Eastern University develops technologies for obtaining, storing and transferring energy, which it uses in the process of creating additional alternative energy sources, including those used at the facilities of the university. Students take an active part in the field of space technologies when creating projects for space satellites and vehicles.

At Tomsk State University, developments are being created using distributed ledger technologies, in particular, a system for protecting intellectual property has been implemented, and a process is underway to transfer all internal work with data to a blockchain. Artificial intelligence technologies are implemented in the educational process using virtual assistants, and are also tested in joint projects with various high-tech companies and corporations. It should be noted that Tomsk University conducts research in the field of space exploration, the equipment for which is created using advanced materials.
Tomsk Polytechnic University uses similar technologies in its educational and scientific activities. The developed artificial intelligence systems are used not only at the university, the university is building digital models for large corporations. Also, artificial intelligence technologies are used to streamline and automate the work of Tomsk University. Scientists work with the technology of obtaining, accumulating and transferring energy on the basis of the existing laboratory "Technologies of hydrogen energy". Research is being carried out in the field of space technologies within the framework of the strategic academic unit "Space Materials Science".

As for Nizhny Novgorod State University, it is one of the founders of a supercomputer consortium of Russian universities, created to solve the problems of effectively using the country's potential, developing and implementing supercomputer technologies in Russian education, science and industry, within which the university is actively working with new computing technologies and distributed ledger technologies. University scientists have created a robot with the possibility of self-learning based on an artificial neural network, which embodies the technologies of artificial intelligence, robotics and neural networks. Developments are underway in the field of multidimensional printing, advanced technologies. It should be noted that the university is working with virtual reality technologies, which are subsequently introduced in various branches of life. In particular, students of the University of Nizhny Novgorod have developed augmented reality glasses for hazardous industries, allowing to secure the work process.

\section{CONCLUSION}

In addition to the highlighted technologies of the new industrial revolution, which are spreading everywhere, universities are implementing new educational technologies that have been formed under the influence of the technological order. The growing demand for qualified personnel and the growth of competition in the educational space created the need for organizing adaptive and lifelong education. Involvement of not only domestic teachers, but also the best professors from other countries in the training process, stimulates the development of international academic mobility for the exchange of experience. The noted technologies of virtual and augmented reality, virtual assistants, as well as international and national educational platforms, the organization of online education, the digitalization of all internal processes are the conditions for the training of specialists necessary in the future, capable of functioning in a rapidly changing economy.

Thus, the analyzed technologies of the fourth industrial revolution, used by universities in the process of carrying out their scientific and educational activities, transform the usual system of higher education management, since universities are becoming one of the main sources of innovations that contribute to the development of the state. They train personnel who meet the needs of the digitalization processes in the regional economy and social 
sectors in the context of the transition to a new level of technological order. This demonstrates the important role of higher education as a driver of the socio-economic development of the country in general and the regions in which they are located, in particular.

\section{REFERENCES}

[1] Popescu. The University as a Regional Development Catalyst: Frameworks to Assess the Contribution of Higher Education to Regional Development // European Economic Recovery and Regional Structural Transformations. 2011, p.10.

[2] L. Blume, T. Brenner, G. Buenstorf. Universities and sustainable regional development: introduction to the special issue // Review of Regional Research. 37(2), 2017, pp.103-109.

[3] M. Gjelsvik. Universities, innovation and competitiveness in regional economies // International Journal of Technology Management. 76 (1-2), 2018, pp.10-31.

[4] A. Bonaccorsi. Addressing the disenchantment: universities and regional development in peripheral regions // Journal of Economic Policy Reform. 20(4), 2016, pp.293-320.

[5] Lendel. The Impact of Research Universities on Regional Economies: The Concept of University Products // Economic Development Quarterly. 24(3), 2010, pp.210-230.

[6] Sevinc H. The role if universities in local economic development: a case of TRA2 region in Turkey // Research Journal of Business and Management. 1, 2014, pp. 448-459.

[7] A. Sterlacchini, R\&D, higher education and regional growth: Uneven linkages among European regions // Research Policy. 2008, 37 (6-7), pp.1096-1107

[8] E. A. Hanushek, Will more higher education improve economic growth? // Oxford Review of Economic Policy. 2016, 32(4), pp.538-552.

[9] Rodnyansky Dmitry, Yasnitskaya Yana «The impact of the non-profit sector on the socio-economic development of the region», INDO american journal of pharmaceutical sciencs, Vol.4, Issue 10, pages 37073712, 2017

[10] Yasnitskaya Y, Rodnyansky D., Dorofeyeva E., Volkova N. «Intersectoral cooperation as a factor of social and economic development of the region: the case of Tatarstan Republic», Proceedings of the 4th International Congress on Interdisciplinary Behavior and Social Science, ICIBSOS, pages 163-166, 2015 